\title{
Cytochrome P450 expression and catalytic activity in coronary arteries and liver of cattle
}

\author{
Emanuela Grasso $^{\mathrm{a}}$, Vincenzo Longo ${ }^{\mathrm{b}}$, Flavio Coceani ${ }^{\mathrm{a}, \mathrm{b}}$, Pier Giovanni Gervasi ${ }^{\mathrm{b}, *}$

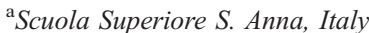 \\ ' Institute of Clinical Physiology CNR, via Moruzzi 1, 56127 Pisa, Italy
}

Received 24 September 2004; received in revised form 22 November 2004; accepted 29 November 2004

Available online 31 December 2004

\begin{abstract}
There is increasing evidence that cytochrome P450 (CYP) enzymes are involved not only in the metabolism of xenobiotics, but also in vascular homeostasis. Among the CYP-derived vasoactive agents, special importance is assigned to endogenous products from arachidonic acid (AA). Specifically, the vasodilator epoxyeicosatrienoic acids (EETs), being linked to the CYP 2B, 2C, and 2J subfamilies, and the vasoconstrictor 20-hydroxyeicosatetraenoic acid (20-HETE) connected instead to the CYP 4A subfamily and, to a lesser degree, to isoforms of the CYP 1A and 2E subfamilies. Here, we have examined the occurrence of functional CYP isoforms in the coronary arteries of cattle by RT-PCR with sequence verification, Western immunoblotting, and analysis of distinct catalytic activities with fluorescent substrate probes. Liver tissue was examined comparatively. Coronary tissue expressed mRNA transcripts and immunoreactive proteins belonging to the CYP $1 \mathrm{~A}, 2 \mathrm{C}, 2 \mathrm{E}$, and $2 \mathrm{~J}$ subfamilies. Appropriate catalytic activity was ascertained with all these CYP species except $2 \mathrm{~J}$. A broader spectrum of CYP enzymes (CYP 1A, 2B, 2C, 2D, 2E, 2J, 3A, 4A subfamilies) was found in liver tissue with catalytic activities exceeding many fold those of coronary tissue. We conclude that bovine coronary arteries are endowed with a full-fledged CYP system with potential for AAlinked vasoregulation through dilator rather than constrictor agents. The same tissue and, to a much larger degree, liver tissue possess the capability of metabolizing xenobiotics via the CYP pathway.
\end{abstract}

(C) 2004 Elsevier B.V. All rights reserved.

Keywords: Cytochrome P450; Cattle; Coronary artery; Liver; Vasoregulation; Metabolism of xenobiotic

\section{Introduction}

The cytochrome P450 (CYP) superfamily comprises a large number of enzymes that are often critical for the oxidative metabolism of endogenous and exogenous compounds [1]. Although CYPs are primarily expressed

Abbreviations: AA, arachidonic acid; BROD, benzyloxyresorufin $O$ debenzylase; BQ-D, 7-benzyloxyquinoline hydroxylase; CYP, cytochrome P450; EDHF, endothelium-derived hyperpolarizing factor; EET, epoxyeicosatrienoic acid; $\mathrm{EF}_{3} \mathrm{C}$-D, 7-ethoxy-4-(trifluoromethyl) coumarin hydroxylase; EROD, ethoxyresorufin $O$-deethylase; 20-HETE, 20 hydroxyeicosatetraenoic acid; $\mathrm{MF}_{3} \mathrm{C}-\mathrm{D}$, 7-methoxy-4-(trifluoromethyl) coumarin hydroxylase; NO, nitric oxide; PG, prostaglandin; PROD, pentoxyresorufin $O$-depentylase

* Corresponding author. Tel.: +39 050 3152701; fax: +39 050 3152166

E-mail address: piergiovanni.gervasi@ifc.cnr.it (P.G. Gervasi). in the liver, they also occur in diverse extrahepatic sites including the intestine, kidney, nasal mucosa, and lung [2-5]. Recent work has also demonstrated their presence in the vascular system where they may play a crucial role in tone regulation through the transformation of arachidonic acid (AA) to epoxygenase (epoxytrienoic acids, EETs) and $\omega$ hydroxylation (20-hydroxyeicosatetraenoic acid, 20-HETE) products [4,6,7]. In fact, it has been shown that the activation of a CYP epoxygenase in the endothelium is an essential step for nitric oxide/prostaglandin $\mathrm{I}_{2}\left(\mathrm{NO} / \mathrm{PGI}_{2}\right)$-independent hyperpolarization of the underlying muscle with the attendant vasodilatation, while 20-HETE is a potent constrictor being formed within the muscle itself $[4,6,7]$. By using RT-PCR, selective inhibitors and inducers of CYPs, Western immunoblotting and immunocytochemical techniques, CYP isoforms belonging to the $2 \mathrm{~B}, 2 \mathrm{C}$ and $2 \mathrm{~J}$ subfamilies have been identified in 
different species as epoxygenases yielding vasoactive EETs [4,6-12]. The formation of 20-HETE, on the other hand, has been linked to the CYP4A subfamily, the contribution from other CYPs, specifically $1 \mathrm{~A}$ and $2 \mathrm{E}$, being minor $[4,7]$.

Many investigations dealing with CYP-derived, vasoactive products have been carried out in coronary vessels [8-13]. However, they have used mainly cell cultures rather than the freshly dissected tissue and, moreover, have been centered on CYPs responsible for the oxidation of AA. It follows that limited information [13] is available on the possible metabolism of other endogenous substrates and xenobiotic compounds. The latter, in particular, could be drugs or procarcinogens whose transformation via CYPs may adversely affect the structure and function of coronary vessels.

The purpose of our investigation was to gain a better insight into the functional organization of the CYP system in the coronary arteries. This was achieved by assessing the expression and catalytic activity of a broad group of CYPs, including forms that may not be involved in the biotransformation of AA. Liver tissue was examined comparatively. Cattle was used as the test animal to ensure an adequate yield of tissue and provide, at the same time, information on a species that has been relatively neglected in previous studies of CYP function [see Ref. [14]].

\section{Materials and methods}

\subsection{Chemicals}

7-Ethoxy-4-trifluoromethyl coumarin, 7-methoxy-4-trifluoromethyl coumarin, 7-hydroxy-4-trifluoromethylcoumarin, resorufin, coumarin, ethoxyresorufin, pentoxyresorufin, and benzyloxyresorufin were supplied from Sigma Chemical (St. Louis, USA). Rabbit polyclonal antibodies against rat CYP 1A1, 2B1, 2E1, 2C11, 3A2, 4A1, human CYP 2D6, 7-benzyloxyquinoline and 7-hydroxyquinoline were purchased from Gentest (Woburn, USA). The rabbit polyclonal antibody against recombinant CYP $2 \mathrm{~J} 2$ was a gift of Dr. D. Zeldin (National Institute of Environmental Health Sciences, Research Triangle Park, NC, USA). All chemicals and reagents were of analytical grade.

\subsection{Preparation of microsomes}

Not castrated, male cattle ( $n=9$; Limousine breed, $15-$ 20 months of age) were supplied by a municipal abattoir (San Miniato-Pisa district). The animals were healthy and had not received any medication for at least 15 days prior to killing. Coronary arteries (epicardial tract) and liver (pooled tissue from all lobes) were collected within 20-40 min of killing and were frozen in liquid nitrogen to be subsequently stored at $-80{ }^{\circ} \mathrm{C}$ for further work-up. Blood vessels, each sample consisting of pooled tissue from three animals, and individual liver specimens were used to prepare microsomes according to a published procedure [15]. Microsomal protein concentration was measured by the method of Lowry et al. [16] with bovine serum albumin as standard. Reference microsomal proteins from Sprague-Dawley rats were used in certain experiments (Western immunoblotting; see below). Surgical procedures and experimental protocols were approved by the Animal Care Committee of the Ministry of Health.

\subsection{Preparation of $R N A$ and $c D N A$}

Total RNA was isolated from coronary arteries and liver with the TriPure Isolation Reagent (Roche Molecular Biochemicals, Indianapolis, USA), as recommended by the manufacturer. Briefly, frozen coronary tissue, each sample being from three animals, and liver $(80-100 \mathrm{mg}$; $n=2$; same for both tissues) were ground to powder in a chilled mortar before being homogenized in TriPure solution $(1 \mathrm{ml})$. The resulting mixture was centrifuged $\left(12,000 \times g ; 10 \mathrm{~min}\right.$ at $\left.4{ }^{\circ} \mathrm{C}\right)$, the aqueous phase was separated and was added $0.2 \mathrm{ml}$ of chloroform. It was then centrifuged again, and the liquid phase was centrifuged a third time after adding $0.5 \mathrm{ml}$ of isopropanol to precipitate the RNA. The ensuing pellet was washed with $1 \mathrm{ml}$ of ethanol-water (7.5:2.5, by volume) before being dissolved into sterile Rnase-free water $(20 \mu \mathrm{l})$. RNA $(2 \mu \mathrm{g})$ was reverse transcribed with $1 \mathrm{U}$ of ThermoScript RT (Invitrogen Life Technologies, Carlsbad, USA) in the presence of random hexanucleotide primers according to the manufacturer's instructions.

Table 1

Sequence of primers used for PCR analysis

\begin{tabular}{|c|c|c|c|}
\hline Gene & Sequence & & $\begin{array}{l}\text { Product } \\
\text { size (bp) }\end{array}$ \\
\hline \multirow[t]{3}{*}{ CYP 1A } & Forward $_{1}$ & GCCNGACCTCTACAGCTT & \multirow[t]{3}{*}{580} \\
\hline & Forward $_{2}$ & GCCAATGTCATCTGTGCC & \\
\hline & Reverse & TGGGATGGTGAAGGGGA & \\
\hline \multirow{3}{*}{ CYP 2B } & Forward $_{1}$ & CATCATCTGCTCCATTGT & \multirow[t]{3}{*}{317} \\
\hline & Forward $_{2}$ & GATGCKGTYATCCACGAG & \\
\hline & Reverse & AGGATGGTGGTGAAGAAG & \\
\hline \multirow[t]{3}{*}{ CYP 2C } & Forward $_{1}$ & СССТCCTGGCCCCACTC & \multirow[t]{3}{*}{300} \\
\hline & Forward $_{2}$ & CATGGATAYGARGCAGTGAA & \\
\hline & Reverse & GGAGCAGATCACATTGCAGG & \\
\hline \multirow[t]{2}{*}{ CYP 2D14 } & Forward & GCTGAAGGAAGAGTTTAACTTAGT & \multirow[t]{2}{*}{393} \\
\hline & Reverse & CTCACCTGCCCTATCACCT & \\
\hline \multirow[t]{3}{*}{ CYP 2E1 } & Forward $_{1}$ & CGGTCGCCCTGCTGGTG & \multirow[t]{3}{*}{650} \\
\hline & Forward $_{2}$ & CCATCTGGAAGCACATCTAC & \\
\hline & Reverse & CTATGGCTTCCAGGCAGGT & \\
\hline \multirow[t]{2}{*}{ CYP 2J } & Forward & CССТCAYTTCAAGATCAACA & \multirow[t]{2}{*}{353} \\
\hline & Reverse & GCAGATGAGGTTTTCTTCAT & \\
\hline \multirow[t]{2}{*}{ CYP 3A28 } & Forward & TGGAACATAGCAAGAACCTC & \multirow[t]{2}{*}{310} \\
\hline & Reverse & TAGCCACCAAAAATAAAGATAG & \\
\hline \multirow[t]{3}{*}{ CYP 4A } & Forward & GAAGTGTGCCTTCAGCC & \multirow[t]{3}{*}{700} \\
\hline & Reverse $_{1}$ & AAGCGNAGCAGGGTCAG & \\
\hline & Reverse $_{2}$ & AAGGGTCAAACACCTCTG & \\
\hline
\end{tabular}

Two primers (external and internal) were used upstream or downstream in certain cases (for details, see text). 


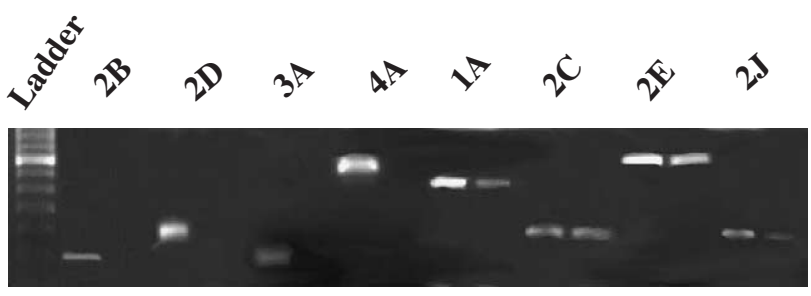

$\begin{array}{lllllllllllllllll}\text { L } & \text { C } & \text { L } & \text { C } & \text { L } & \text { C } & \text { L } & \text { C } & \text { L } & \text { C } & \text { L } & \text { C } & \text { L } & \text { C } & \text { L } & \text { C }\end{array}$

Fig. 1. Gel electrophoresis of RT-PCR-amplified CYPs mRNA from bovine coronary (C) and liver (L) tissues. First line contains the DNA molecular weight markers (100 pb increments). Size of the PCR products was as follows: CYP 1A, 0.52 Kpb; CYP 2B, 0.36 Kbp; CYP 2C, $0.30 \mathrm{Kbp}$; CYP 2D, 0.39 Kbp; CYP 2E, 0.65 Kbp; CYP 2J, 0.35 Kbp; CYP 3A, $0.35 \mathrm{Kbp}$; CYP 4A, $0.7 \mathrm{Kbp}$.

\subsection{RT-PCR and sequence analysis}

Primers for CYP 1A, 2B, 2C, 4A subfamilies were constructed through the identification of conserved regions of homologous isoforms being retrieved from GenBank. The CRUSTAL program for multiple sequence alignment was used for this purpose. The following comparisons were made: CYP 1A subfamily (murine CYP 1A1, GenBank accession no.KO2246; rabbit CYP 1A1, GenBank accession no.DOO212; ovine CYP 1A1, GenBank accession no.579795), CYP 2B subfamily (murine CYP 2B1, GenBank accession no.J00719; rabbit CYP 2B5, GenBank accession no.M18820; canine CYP 2B11, GenBank accession no.M92447), CYP 2C subfamily (rabbit CYP 2C5, GenBank accession no.M55664; human CYP 2C8, Gen-
Bank accession no.M17397; human CYP 2C9, GenBank accession no.D00173), and CYP 4A subfamily (human CYP 4A11, GenBank accession no.L04751; rabbit CYP 4A7, GenBank accession no.J05150). As reported in Table 1, three oligonucleotides were chosen for each of these subfamilies to perform SEMI-NESTED PCR. In the case of the CYP 2J subfamily, primers corresponded to those used previously for the identification of the porcine and human isoforms [8] (Table 1). The remaining primers were derived from known bovine sequences (CYP 2D14, GenBank accession no.X68481; CYP 2E1, GenBank accession no.AJ001715; CYP 3A28, GenBank accession no.Y10214) (Table 1). Only one pair of primers was used for the PCR analysis of CYP 2D, 2E, 2J, and 3A isoforms.

cDNA $(2 \mu \mathrm{g})$ was used for the amplification reactions (35 cycles) after being denaturated at $95{ }^{\circ} \mathrm{C}$ for $2 \mathrm{~min}$, and products were separated on agarose gel $\left(1.5 \% 95{ }^{\circ} \mathrm{C} \mathrm{w} \mathrm{v}{ }^{-1}\right)$ and subsequently stained with ethidium bromide. The expected amplified DNA fragments were: $580 \mathrm{bp}$ for CYP $1 \mathrm{~A}, 317 \mathrm{bp}$ for 2B, $300 \mathrm{bp}$ for 2C, $393 \mathrm{bp}$ for 2D14, $650 \mathrm{bp}$ for $2 \mathrm{E} 1,353 \mathrm{bp}$ for $2 \mathrm{~J}, 310 \mathrm{bp}$ for $3 \mathrm{~A} 28$, and $700 \mathrm{bp}$ for $4 \mathrm{~A}$. For further verification, PCR products were purified by a Qiaquick Kit (QUIAGEN, Mi, Italy), as indicated by the manufacturer, and were sequenced by automated fluorescent cycle sequencing (AGI, PD, Italy).

\subsection{Western immunoblotting}

Microsomal proteins from both coronary arteries $(30 \mu \mathrm{g})$ and liver $(5 \mu \mathrm{g})$ were separated according to Laemmli [17] on

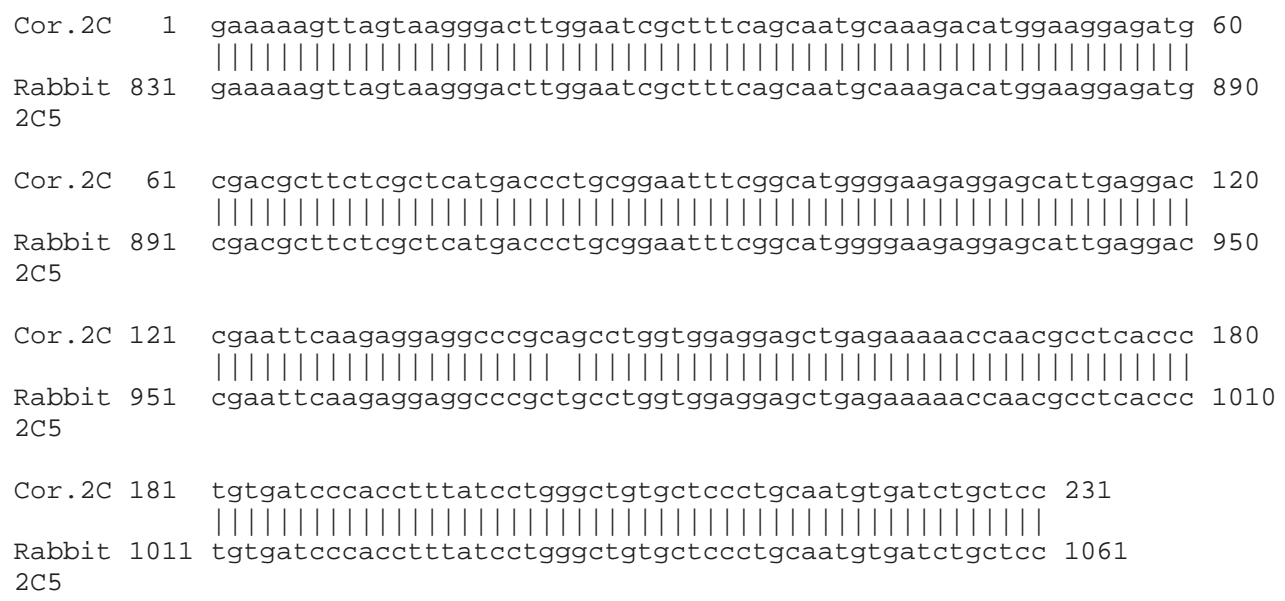

Fig. 2. Nucleotide and aminoacid sequences of the bovine coronary artery CYP $2 \mathrm{C}$ fragment vs. rabbit CYP $2 \mathrm{C} 5$. 
(Fig. 1). No signal was detected instead for CYP 2B, 2D, 3A, and 4A isoforms (Fig. 1). However, all CYPs isoforms being investigated, whether occurring or not in the vascular tissue, were found in the liver (Fig. 1).

The identity of PCR products from coronary arteries was confirmed through sequence analysis. CYP 2E fragment proved to be identical to the bovine CYP 2E1 being reported in the GenBank. Nucleotide and amino acid sequences of the CYP 2C fragment coincided (98\%) with those of rabbit CYP 2C5 (Fig. 2) and were highly concordant with those of human CYP 2C8 and 2C9 (data not shown). The same sequences for CYP $1 \mathrm{~A}$ were, respectively, $79 \%$ and $58 \%$ homologous to the ovine CYP 1A1 (Fig. 3), while in the case of the CYP 2J fragment there was a $79 \%$ and $69 \%$ homology with rabbit CYP 2J1 (Fig. 4).

\subsection{Western immunoblotting}

Protein expression for CYP subfamilies, as evidenced by Western immunoblotting with a host of antibodies (anti-rat,
1A1, 2B1, 2C11, 2E1, 3A2, 4A1; anti-human, 2D6; antirecombinant isoform, $2 \mathrm{~J} 2$ ), accorded with data from mRNA analysis.

Results are exemplified in Fig. 5. Anti CYP 1A1 recognized two proteins bands, conceivably CYP $1 \mathrm{~A} 1$ and CYP 1A2, in bovine and rat liver microsomes. A similar pattern has been reported by others in cattle but not rat [14]. Conversely, only the band of higher molecular weight, i.e. CYP $1 \mathrm{~A} 1$, was clearly visible in the coronary sample. When microsomes were probed with the antibody against CYP 2C11, an equally strong signal was detected in all tissues. On the other hand, in accord with earlier data [24], anti CYP 2B1 recognized in the bovine liver a protein band of similar molecular weight to that of the rat, while a band of higher molecular weight was seen in the coronary microsomes. The latter finding likely denotes the presence of a crossreacting protein other than CYP 2B. When the antibody to CYP 2E1 was used, a single band of comparable molecular weight was noted in all specimens, whether from cattle or rat. On the other hand, with the

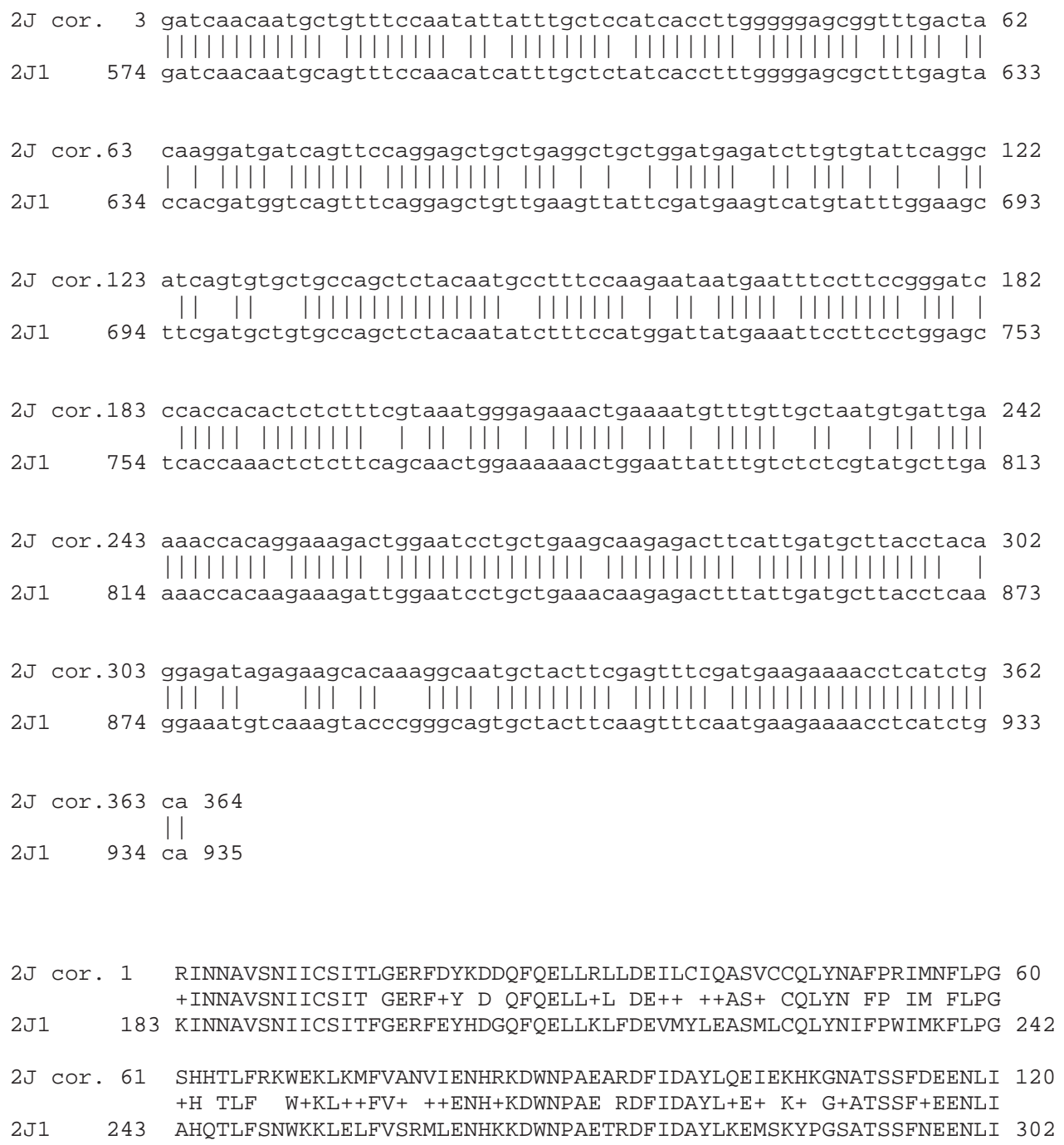

Fig. 4. Nucleotide and aminoacid sequences of the bovine coronary artery CYP 2J fragment vs. rabbit CYP 2J1. 


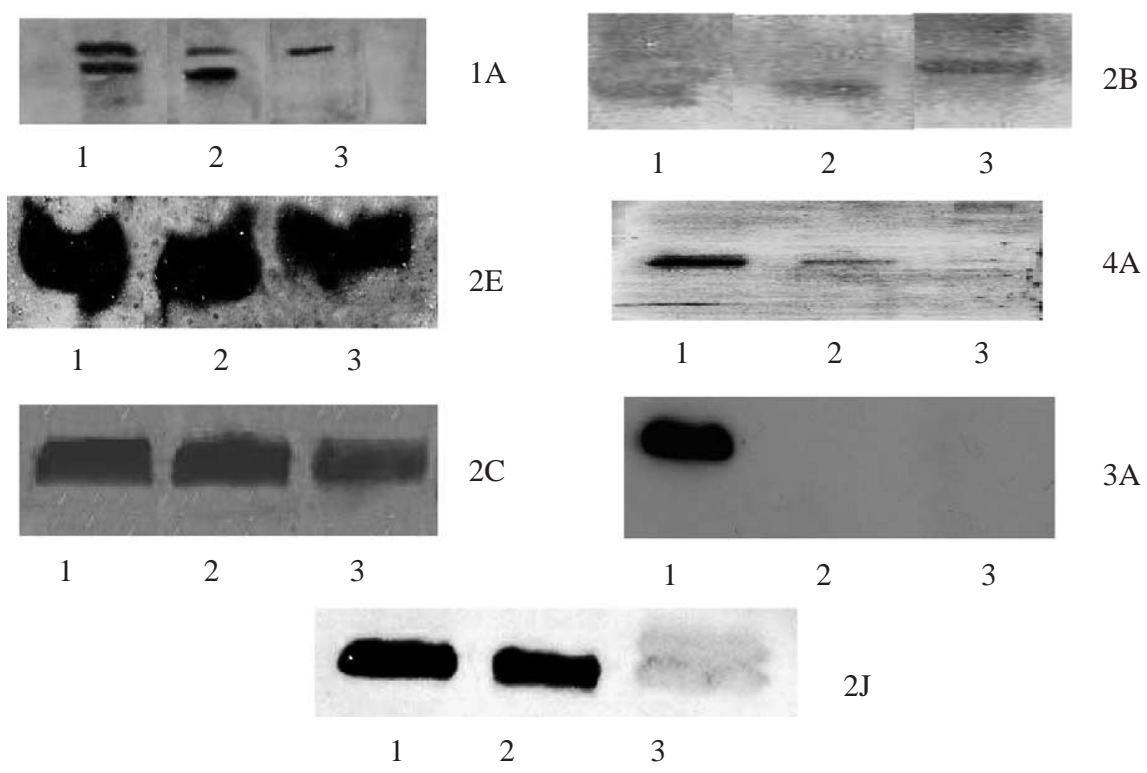

Fig. 5. Immunoblot analysis of CYP expression in bovine liver (lane 2) and coronary arteries (lane 3). Reactive proteins belonged to CYP 1A, 2B, 2C, 2E, 2J, $3 \mathrm{~A}$, and $4 \mathrm{~A}$ subfamilies. Microsomes from control rat liver (lane 1) served as a reference. Note that, in the case of CYP 1A, lane 1 used liver miocrosomens from $\beta$-naphtoflavone-treated rat as reference.

CYP 2J2 antibody two protein bands were recognized in the coronary microsomes, unlike liver ones, possibly due to the presence in this extrahepatic tissue of two CYP2J isoforms. Immunoblotting with antibodies to CYP $4 \mathrm{~A} 1$ and 2D6 (not shown) could not detect any signal in the coronary microsomes, while these reactive proteins were found in the liver of both species. Equally absent was a response when coronary microsomes were challenged with the CYP $3 \mathrm{~A} 2$ antibody, and this negative result was also evident in cattle, but not rat, liver microsomes.

\subsection{Monooxygenase activities}

As reported in Table 2, coronary artery microsomes showed NADPH-cytochrome P450 reductase activity, although its value was considerably lower than in the liver.

Table 2

CYP content and monooxygenase activity in microsomes from coronary artery and liver of cattle

\begin{tabular}{llc}
\hline & Coronary artery & Liver \\
\hline CYP content & nd & $0.46 \pm 0.09$ \\
CYP reductase & $3.8 \pm 0.9$ & $53 \pm 6$ \\
EROD (CYP 1A) & $4.1 \pm 2.2$ & $113 \pm 25$ \\
PROD (CYP 2B) & $0.8 \pm 0.3$ & $2.8 \pm 0.8$ \\
$\mathrm{EF}_{3} \mathrm{C}-\mathrm{D}$ (CYP 2B/2E) & $9.9 \pm 1.8$ & $207 \pm 33$ \\
$\mathrm{BROD}($ CYP 2B/3A) & $1.1 \pm 0.5$ & $79 \pm 19$ \\
$\mathrm{MF}_{3} \mathrm{C}-\mathrm{D}$ (CYP 2C) & $8.2 \pm 2.1$ & $83 \pm 18$ \\
$\mathrm{BQ}-\mathrm{D}$ (CYP 3A) & nd & $246 \pm 54$ \\
\hline
\end{tabular}

Values are means \pm S.D. $(n=3$ or 4$)$ and are expressed as nmol mg ${ }^{-1}$ protein (CYP content), $\mathrm{nmol} \mathrm{mg}^{-1}$ protein $\mathrm{min}^{-1}$ (CYP reductase), or pmol mg $\mathrm{m}^{-1}$ protein $\min ^{-1}$ (CYP marker activity). Individual marker activities are listed with their related CYP subfamily in parenthesis. nd=not detectable.
CYP content, on the other hand, was measurable in liver but not coronary tissue.

Monooxygenase activities were assessed with fluorescent CYP substrates to enhance the selectivity and sensitivity of the assays (Table 2). Under these conditions, coronary microsomes exhibited consistent levels of activity for EROD, PROD, $\mathrm{EF}_{3} \mathrm{C}-\mathrm{D}, \mathrm{BROD}$, and $\mathrm{MF}_{3} \mathrm{C}-\mathrm{D}$ that are known markers, respectively, for members of the CYP $1 \mathrm{~A}$, $2 \mathrm{~B}, 2 \mathrm{~B} / 2 \mathrm{E}, 2 \mathrm{~B} / 3 \mathrm{~A}$, and $2 \mathrm{C}$ subfamilies in the rat or other mammals $[21,22,25]$. Conversely, no activity was found for BQ-D which identifies the CYP 3A subfamily. Liver tissue, as expected, gave a positive reaction with all markers, with values exceeding many fold those of coronary tissue.

\section{Discussion}

Although the formation of various CYP-based AA metabolites (EETs and HETEs) has been reported in cultured cells from bovine coronary artery [12,26], no information is available on the actual occurrence of CYPs in the same tissue. Our study demonstrates the presence of members of the CYP $1 \mathrm{~A}, 2 \mathrm{C}, 2 \mathrm{E}, 2 \mathrm{~J}$ subfamilies in the bovine coronary tissue. This finding, which is based on the concerted use of diverse investigational tools (RT-PCR, Western immunoblotting, assay of catalytic activity for all CYP species except 2J), accord with the data in literature. Since substrate probes used in the present study had been established for rat and human CYPs and immunoblottings were also performed with antibodies raised against rat and human antigens, a note of caution must be introduced when applying these tools to bovine proteins. However, the isoforms found in the bovine coronary tissue have also 
been detected in cultured endothelial cells from pig [10] and human [13] coronary arteries. The only inconsistency in comparing our data with those of others concerns CYP 2B and CYP $3 \mathrm{~A}$ whose presence has previously been reported in human, although not porcine, cells $[10,13]$. Regarding CYP 2B, however, our results are also not univocal since the absence of an appropriate transcript (see Fig. 1) was associated with a positive response in marker enzyme reactions (PROD, BROD; see Table 2), while Western immunoblotting showed a reactive band not precisely coincident with the reference (see Fig. 5). Perhaps, there is in the tissue a, hitherto unidentified, protein not belonging to the CYP 2B subfamily, but yet closely allied to it, that may sustain a marginal enzymic reaction. Liver tissue, on the other hand, is endowed with a broader spectrum of CYPs, each exhibiting much higher catalytic activity compared to the enzyme complement in coronary tissue. Similar findings have been reported by others in the same species [14]. However, although expected, the limited CYP expression in coronary arteries vis-à-vis the liver is possibly an underestimate of the actual situation since some minor isoform might have been missed due to the lack of specific bovine probes.

Bovine coronary tissue did not show any isoform belonging to the CYP 4A subfamily. The result might be expected since the vasoconstrictor 20-HETE, mainly formed through CYP 4A, had not been detected in cultured bovine coronary artery cells $[12,26]$. In this respect, the coronary artery differs from other blood vessels, including those of brain and kidney, in which 20-HETE is assigned a role in the maintenance of muscle tone $[4,6,7]$. Hence, in considering the possible biotransformation of AA, one may conclude that bovine coronary arteries generate primarily epoxygenaselinked vasodilator products being identified with the endothelium-derived hyperpolarizing factor (EDHF) $[4,6,7]$. The implications of such a finding for normal vascular homeostasis remain to be elucidated. Nevertheless, one may already surmise that the AA/CYP complex has an uneven functional arrangement through the vascular tree with vasodilator and vasoconstrictor actions being mutually balanced, or unbalanced, in their expression depending on the particular site.

A similar non-uniform organization may occur with any other CYP-based, vasoregulatory agent originating from endogenous sources [7,27]. CYP1A and $2 \mathrm{E}$ isoforms, in particular, may promote $\mathrm{AA}$ hydroxylation at the $\mathrm{C}_{19}$ carbon atom position [7]. A similar AA hydroxylation and vascular regulation may occur also in the rabbit pulmonary artery where the CYP $1 \mathrm{~A}$ and $2 \mathrm{E}$ along with $\mathrm{CYP} 2 \mathrm{~B}$ and $2 \mathrm{C}$ have been immunodetected. On the contrary, other vessels in the same species such as the carotid artery and aorta, do not exhibit CYP-based AA metabolism, thus implying that vascular homeostasis relies on other agents [28].

The presence of CYP isoforms in coronary artery tissue has also some bearing on pathological processes, specifically the development of atherosclerotic lesions. The CYP $2 \mathrm{~J}$ is abundant in the endothelium and is thought to protect against hypoxia-reoxygenation injury [29]. On the other hand, considering the facile induction of certain isoforms, such as CYP 1A, by environmental pollutants and drugs [30], an excess amount of reactive oxygen species could be formed within the vessel wall and exert a damaging effect particularly on the endothelium. In fact, a vicious cycle could be envisaged whereby endothelial dysfunction, with the attendant lesser formation of NO, leads to the removal of an inhibitory influence on CYP function [4] and, ultimately, promotes a self-sustained pathogenetic sequence. The presence of CYP 2E1 in coronary tissue is also noteworthy in this connection. This enzyme, which has been detected in various extrahepatic tissues including lung $[2,3]$, catalyses the oxidation of several substances of low molecular weight including many polar and lipophilic solvents [31]. Although it is unlikely that coronary arterial cells play a major role in xenobiotic biotransformation, a tissue-specific metabolism can be important as local noxa. Thus, as the exposure to volatile solvents is common as well as their presence in blood, their bioactivation to toxic intermediates in the coronary arteries may be expected. Furthermore, CYP 2E1, unlike CYP 2J2 [29], is prone to generate ROS from CYP uncoupling cycle with the attendant possibility of a cytotoxic action and apoptosis [32]. It is, in fact becoming increasingly evident that uncontrolled formation of ROS is a key factor for cell damage and the aging process [33].

A final comment relates to the expression of CYPs in the liver. The breed of cattle used has a CYP complement comparable to that of the non-induced cattle breed studied earlier [14]. Coincidentally, the same finding confirms that this domestic animal, of paramount importance for the food chain, is equipped with adequate systems for the degradation of foreign chemicals.

In conclusion, our study proves that the bovine coronary artery is endowed with a functional CYP system comprising several isoforms. The character of these isoforms implies the operation in the tissue of an epoxygenase pathway with vasodilator properties. This system as a whole is also liable to excess activation by xenobiotics with implications for the pathogenesis of coronary vascular disease.

\section{Acknowledgements}

E. G. was the recipient of a graduate studentship from the Scuola Superiore S. Anna. The assistance of C. Raggi, A. Salvetti and S. Nencioni in some experiments is gratefully acknowledged. The antibody against CYP $2 \mathrm{~J} 2$ was kindly provided by Dr. D. Zeldin.

\section{References}

[1] D.R. Nelson, L. Koymans, T. Kamataki, J.J. Stegeman, R. Feyereisen, D.J. Waxman, M.R. Waterman, O. Gotoh, M.J. Coon, R.W. Estabrook, I.C. Gunsalus, D.W. Nebert, P-450 superfamily: update on new sequence, gene mapping, accession numbers and nomenclature, Pharmacogenetics 6 (1996) 1-42. 
[2] F. Pons, M. Haag, A. Lugnier, N. Frossard, Cytochrome P450 in the lung, Eur. Respir. Rev. 10 (2000) 253-256.

[3] V. Longo, M. Ingelman-Sundberg, G. Amato, A. Salvetti, P.G. Gervasi, Effect of starvation and chlormethiazole on cytochrome P450s of rat nasal mucosa, Biochem. Pharmacol. 59 (2000) 1425-1432.

[4] I. Fleming, Cytochrome P450 enzymes in vascular homeostasis, Circ. Res. 89 (2001) 753-762.

[5] J.W. Lohr, G.R. Willsky, M.A. Acara, Renal drug metabolism, Pharmacol. Rev. 50 (1998) 107-141.

[6] D.C. Zeldin, Epoxygenase pathways of arachidonic acid metabolism, J. Biol. Chem. 276 (2001) 36059-36062

[7] J.H. Capdevila, R.C. Harris, J.R. Falck, Microsomal cytochrome P450 and eicosanoid metabolism, Cell. Mol. Life Sci. 59 (2002) 780-789.

[8] B. Fisslthaler, N. Hinsch, T. Chataigneau, R. Popp, L. Kiss, R. Busse, I. Fleming, Nifedipine increases cytochrome P4502C expression and endothelium-derived hyperpolarizing factor-mediated responses in coronary arteries, Hypertension 36 (2000) 270-275.

[9] K. Node, Y. Huo, X. Ruan, B. Yang, M. Spiecker, K. Ley, D.C. Zeldin, J.K. Liao, Anti-inflammatory properties of cytochrome P450 epoxygenase-derived eicosanoids, Science 285 (1999) 1276-1279.

[10] B. Fisslthaler, R. Popp, L. Kiss, M. Potente, D.R. Harder, I. Fleming, R. Busse, Cytochrome P450 2C is an EDHF synthase in coronary arteries, Nature 401 (1999) 493-497.

[11] M. Hacker, A.T. Bara, J. Bauersachs, R. Busse, Characterization of endothelium-derived hyperpolarizing factor as a cytochrome P-450derived arachidonic acid metabolite in mammals, J. Physiol. 481 (1994) 407-414.

[12] M. Rosolowsky, W.B. Campbell, Role of PGI2 and epoxyecosatrienoic acid in relaxation of bovine coronary arteries to arachidonic acid, Am. J. Physiol. 264 (1993) H327-H335.

[13] J. Borlak, M. Walles, K. Levsen, T. Thum, Verapamil: metabolism in cultures of primary human coronary arterial endothelial cells, Drug Metab. Dispos. 31 (2003) 888-891.

[14] S. Sivapathasundaram, P. Magnisali, N.G. Coldham, L.C. Howells, M.J. Sauer, C. Ioannides, A study of the expression of the xenobioticmetabolising cytochrome $\mathrm{P} 450$ proteins and of testosterone metabolism in bovine liver, Biochem. Pharmacol. 62 (2001) 635-645.

[15] V. Longo, A. Mazzaccaro, F. Naldi, P.G. Gervasi, Drug-metabolizing enzymes in liver, olfactory, and respiratory epithelium of cattle, J. Biochem. Toxicol. 6 (1991) 123-128.

[16] O.H. Lowry, N.J. Rosebrough, A.L. Farr, R.J. Randall, Protein measurement with the Folin phenol reagent, J. Biol. Chem. 193 (1951) 265-275.

[17] U.K. Laemmli, Cleavage of structural proteins during the assembly of the head of bacteriophage T4, Nature 227 (1970) 680-685.

[18] T. Omura, R. Sato, The carbon-monoxide binding protein of liver microsomes: I. Evidence for its hemoprotein nature, J. Biol. Chem. 239 (1964) 2370-2378.
[19] B.S.S. Masters Jr., C.H. William, H. Kamin, The preparation and properties of microsomal NADPH-cytochrome $c$ reductase from pig liver, in: R.W. Estabrook, E.E. Pulman (Eds.), Methods in Enzymology, vol. 10, Academic Press, New York, 1967, pp. 565-573.

[20] K.R. Krijgsheld, T.E. Gram, Selective induction of renal microsomal cytochrome P-450-linked monooxygenases by 1,1-dichloroethylene in mice, Biochem. Pharmacol. 33 (1984) 1951-1956.

[21] A. Ghosal, N. Hapangama, Y. Yuan, L.V. Favreau, J.R. Palamanda, J.E. Partick, M.N. Cayen, S. Zbaida, Microtiter plate-based assay for rapid determination of enzyme activities of 13 P-450 supersomes and human liver microsomes, Drug Metab. Rev. 32 (2000) 188.

[22] S. Ekins, M. VandenBranden, B.J. Ring, S.A. Wrighton, Examination of purported probes of human CYP2B6, Pharmacogenetics 7 (1997) $165-179$.

[23] D.M. Stresser, A.P. Blanchard, S.D. Turner, J.C. Erve, A.A. Dandeneau, V.P. Miller, C.L. Crespi, Substrate-dependent modulation of CYP3A catalytic activity: analysis of 27 test compounds with four fluorimetric substrates, Drug Metab. Dispos. 28 (2000) 1440-1448.

[24] A. Aitio, A simple and sensitive assay of 7-ethoxycoumarin deethylation, Anal. Biochem. 85 (1978) 488-491.

[25] S. Ono, T. Hatanaka, H. Hotta, T. Satoh, F.J. Gonzalez, M. Tsutsui, Specificity of substrate and inhibitor probes for cytochrome P450s: evaluation of in vitro metabolism using cDNA-expressed human P450s and human liver microsomes, Xenobiotica 26 (1996) 681-693.

[26] M. Rosolowsky, W.B. Campbell, Synthesis of hydroxyeicosatetraenoic (HETEs) and epoxyeicosatrienoic acids (EETs) by cultured bovine coronary artery endothelial cells, Biochim. Biophys. Acta 1299 (1996) 267-277.

[27] D.W. Nebert, Drug-metabolising enzymes in ligand-modulated transcription, Biochem. Pharmacol. 47 (1994) 25-37.

[28] E.R. Jacobs, D.C. Zeldin, The lung HETEs (and EETs) up, Am. J. Phys. 260 (2001) H1-H10.

[29] B.Y. Yang, L. Graham, S. Dikalov, R.P. Mason, J.R. Falk, J.K. Liao, D.C. Zeldin, Overexpression of cytochrome P450 CYP2J2 protects against hypoxia-reoxygenation injury in cultured bovine aortic endothelial cells, Mol. Pharmacol. 60 (2001) 310-320.

[30] D.F. Lewis, Quantitative structure-activity relationships in substrates, inducers, and inhibitors of cytochrome P4501 (CYP1), Drug Metab. Rev. 29 (1997) 589-650.

[31] F.P. Guengerich, D.H. Kim, M. Iwasaki, Role of human cytochrome P4502E1 in the oxidation of many low molecular weight cancer suspects, Chem. Res. Toxicol. 4 (1991) 168-179.

[32] A.A. Caro, A.I. Cederbaum, Oxidative stress, toxicology and pharmacology of CYP 2E1, Annu. Rev. Pharmacol. Toxicol. 44 (2004) $27-42$.

[33] T. Finkel, Oxygen radical and signaling, Curr. Opin. Cell Biol. 10 (1998) $248-253$ 